\title{
Strategies that Reduce Post-endoscopic Submucosal Dissection Bleeding
}

\author{
Da Hyun Jung, Jun Chul Park \\ Department of Gastroenterology, Severance Hospital, Yonsei University College of Medicine, Seoul, Korea
}

\begin{abstract}
Bleeding after endoscopic submucosal dissection (ESD), one of the most common postprocedural adverse events, is the main cause of increased readmission rates and hospital costs. Generally, the incidence of post-ESD bleeding is estimated to be about 5\%. However, the incidence of bleeding is particularly increased in high-risk patients. In particular, it has an incidence of over $50 \%$ in patients that use antithrombotic agents. The well-known risk factors for post-ESD bleeding include antithrombotic therapy, lesions in the proximal stomach, specimen size $>4 \mathrm{~cm}$, and concomitant renal disease. Currently, the number of patients at a high risk of post-ESD bleeding has been increasing. This may be due to the aging society and the increase in the usage of antithrombotic agents. Therefore, several strategies have been employed to prevent post-ESD bleeding. These strategies include acid inhibition therapy, preventive hemostasis using Doppler endoscopic ultrasound and artery-selective clipping, second look endoscopy, the closings method, and the shield methods. However, these methods are technically demanding, which hinders their wide usage in clinical practice. Recently, several hemostatic powders have been developed and clinically used in the treatment of gastrointestinal bleeding. In this article, we review the risk factors for post-ESD bleeding and the recently introduced prevention methods. Moreover, we aimed to explore realistic and appropriate strategies for the prevention of post-ESD bleeding. (Korean J Helicobacter Up Gastrointest Res 2021;21:194-202)
\end{abstract}

Key Words: Bleeding; Endoscopic submucosal dissection; Hemostasis

\section{INTRODUCTION}

Endoscopic submucosal dissection (ESD) has been recommended as a standard treatment for gastric neoplasms. ${ }^{1,2}$ Unlike endoscopic mucosal resection (EMR), ESD allows en bloc resection regardless of lesion size, which contributes to decreasing local recurrence. However, ESD is technically demanding and has a longer procedure time than EMR. In addition, ESD has a higher risk of procedure-related adverse events than EMR. The common adverse events after ESD are bleeding, perforation, postprocedural electrocoagulation syndrome, and aspiration pneumonia, ${ }^{3}$ among which postESD bleeding is one of the most frequent. Bleeding is the main cause of increased readmission rates and hospital costs after ESD. Generally, the incidence of post-ESD bleeding is estimated to be $1.8 \sim 15.6 \%{ }^{4-8}$ However, the incidence of bleeding is particularly increased in high-risk patients, reach-

Received: July 5, 2021 Revised: July 19, 2021 Accepted: August 6, 2021

Corresponding author: Jun Chul Park

Department of Gastroenterology, Severance Hospital, Yonsei University College of Medicine, 50-1 Yonsei-ro, Seodaemun-gu, Seoul 03722, Korea

Tel: +82-2-2228-2272, Fax: +82-2-393-6884, E-mail: JUNCHUL75@yuhs.ac ing $61.5 \%$ in those using anticoagulant agents. ${ }^{9}$ With the aging of society, the number of patients with a high risk of bleeding has increased owing to the increasing use of antithrombotic agents. Post-ESD bleeding is generally defined as clinical or laboratory signs of bleeding with urgent endoscopy findings showing bleeding in the stomach or a requirement for endoscopic hemostasis. To date, several strategies have been attempted to prevent post-ESD bleeding, such as mucosal closure with a detachable snare and clips, use of an overstitch endoscopic suturing device, application of polyglycolic acid (PGA) sheets, and bio-sheet graft therapy. However, these methods are technically demanding, which hinders their wide use in clinical practice. In this review, we summarize the risk factors and introduce preventive methods for post-ESD bleeding.

\section{RISK FACTORS FOR POST-ESD BLEEDING}

Until now, many studies have evaluated the risk factors for post-ESD bleeding. Antithrombotic drugs, lesions in the proximal stomach, and specimen size $>4 \mathrm{~cm}$ have been re-

Copyright $\odot 2021$ Korean College of Helicobacter and Upper Gastrointestinal Research

(a) The Korean Journal of Helicobacter and Upper Gastrointestinal Research is an Open-Access Journal. All articles are distributed under the terms of the Creative Commons Attribution Non-Commercial License (http:// creativecommons.org/licenses/by-nc/4.0) which permits unrestricted non-commercial use, distribution, and reproduction in any medium, provided the original work is properly cited. 
ported as well known risk factors for post-ESD bleeding (Table 1). In addition, chronic kidney disease and hemodialysis also have been demonstrated as risk factors for post-ESD bleeding. ${ }^{6,10,11}$ Post-ESD iatrogenic ulcers may heal slowly in patients with chronic kidney disease owing to low albumin levels and blood vessel disease. In addition, the high incidence of bleeding is attributed to the fact that dialysis activates blood platelets through the interaction of blood with artificial membranes and anticoagulants. The post-ESD bleeding rate was reported to reach $>50 \%$ in patients who continued using antithrombotic agents in previous studies, ${ }^{9,12,13}$ and the odds ratio of bleeding with continuation of antithrombotics was up to 8.39 in a meta-analysis study. ${ }^{8}$ At present, many patients undergoing ESD are prescribed antithrombotics because of various underlying illnesses, such as cerebrovascular accidents or cardiovascular diseases. ${ }^{13}$ In our previous study, we used variable statistical methods to analyze 5,080 patients with gastric neoplasms treated with ESD. ${ }^{14}$ We developed a simple and easy-to-apply predictive tree model based on three risk factors (ongoing antithrombotic agent use, resected specimen size $\geq 49 \mathrm{~mm}$, and patient age $<62$ years), which could help endoscopists identify patients at a high risk of bleeding. This model revealed age as a significant risk factor for post-ESD bleeding. In previous studies, younger age was related to post-ESD bleeding. The higher risk of bleeding in younger patients may be attributable to their higher physical activity level and more gastric acid secretion than those in older people. However, as the effects of age on post-ESD bleeding need to be analyzed with other objective parameters, further studies are needed. In addition, the antithrombotic therapy increases the risk of post ESD bleeding. Therefore, when endoscopists perform ESD in patients with antithrombotic therapy, they should consider the following issues: the bleeding risk of the procedure, the effect of the antithrombotic drugs on the bleeding risk and the risk of a thromboembolic event related to periprocedural interruption of antithrombotic agents. The probability of a thromboembolic event related to the temporary interruption of antithrombotic therapy for an ESD depends on the indication for antithrombotic therapy and individual patient characteristics. In

Table 1. Previous Studies on the Risk Factors for Bleeding after Endoscopic Submucosal Dissection of Gastric Lesions

\begin{tabular}{|c|c|c|c|}
\hline Study & $\begin{array}{l}\text { Number of } \\
\text { lesions }\end{array}$ & PEB (\%) & Risk factors (multivariate analysis) \\
\hline Takahashi et al. $^{45}$ (2014) & 459 & 5.0 & Younger age, lesions in the lower segment, large size of the resected specimen \\
\hline Nakamura et al..$^{46}(2012)$ & 544 & 7.0 & Low platelet count $\left(<150 \times 10^{9} / \mathrm{L}\right)$, and positive or indeterminate lateral margin \\
\hline Yano et al. ${ }^{6}(2017)$ & 1,767 & 8.5 & $\begin{array}{l}\text { Lesions at the distal stomach, procedure time } \geq 90 \text { minutes, specimen size } \geq 4 \mathrm{~cm} \text {, } \\
\text { antithrombotic therapy }\end{array}$ \\
\hline Toyokawa et al. ${ }^{47}$ (2012) & 1,123 & 5.0 & Aged $\geq 80$ years, a long procedure time \\
\hline Koh et al..$^{5}(2013)$ & 1,192 & 5.3 & Specimen size $>4 \mathrm{~cm}$ \\
\hline Sanomura et al..$^{48}(2018)$ & 1,243 & 4.1 & $\begin{array}{l}\text { Dialysis, anticoagulant (warfarin and heparin replacement/DOAC), operation time } \\
\geq 75 \text { minutes }\end{array}$ \\
\hline Matsumura et al. ${ }^{11}$ (2014) & 425 & 4.7 & Heparin replacement, CKD undergoing, hemodialysis, specimen size $\geq 4 \mathrm{~cm}$ \\
\hline Ebi et al. ${ }^{49}(2014)$ & 186 & 4.2 & Hypertension, depressed-type tumors \\
\hline Miyahara et al. ${ }^{50}(2012)$ & 1,190 & 6.9 & Tumor location, resected tumor size, scarring in lesion \\
\hline Kim et al. ${ }^{32}(2014)$ & 441 & 4.1 & Large tumor size $(>2 \mathrm{~cm})$ \\
\hline Libânio et al. ${ }^{31}(2016)^{\mathrm{a}}$ & 62 studies & 5.1 & $\begin{array}{l}\text { Male sex, cardiopathy, antithrombotic drugs, cirrhosis, chronic kidney disease, tumor } \\
\text { size }>20 \mathrm{~mm} \text {, resected specimen size }>30 \mathrm{~mm} \text {, localization in the lesser curvature, } \\
\text { flat/depressed morphology, carcinoma histology, ulceration, procedure duration }>60 \\
\text { minutes, the use of histamine- } 2 \text { receptor antagonists instead of proton pump inhibitors }\end{array}$ \\
\hline Choe et al. ${ }^{14}(2021)$ & 5,080 & 5.1 & $\begin{array}{l}\text { Ongoing antithrombotics during procedure, cancer pathology on biopsy, piecemeal } \\
\text { resection }\end{array}$ \\
\hline Hatta et al. ${ }^{51}(2021)$ & 8,291 & 4.7 & $\begin{array}{l}\text { CKD with hemodialysis, aspirin, P2Y12RA, cilostazol, warfarin, DOAC, interruption } \\
\text { of agents, multiple tumors, tumor size }>30 \mathrm{~mm} \text {, lower third location }\end{array}$ \\
\hline
\end{tabular}

PEB, post endoscopic submucosal dissection bleeding; DOAC, direct oral anticoagulants; CKD, chronic kidney disease.

${ }^{a}$ This study is a meta-analysis. 
addition, the longer interruption of antithrombotic therapy increases the thromboembolic events. Therefore, reinitiation time of antithrombotic agents after the procedure is also important. And, when holding and restarting an antithrombotic, time to maximum effect, half-life, and excretion of the drug were also considered. According to the recent guidelines of the American Society of Gastrointestinal Endoscopy and the European Society of Gastrointestinal Endoscopy recommend restarting antithrombotic agents as soon as possible. ${ }^{15,16}$ However, there is no well-designed prospective study about the timing of resumption of antithrombotic agents. Therefore, it is important for endoscopists to explore strategies for reducing post-ESD bleeding and to carefully monitor the occurrence of this adverse event in high-risk patients with antithrombotic use.

\section{METHODS FOR PREVENTING POST-ESD BLEEDING}

Fundamentally, the use of acid inhibitors such as proton pump inhibitors (PPIs) and $\mathrm{H}_{2}$ receptor antagonists is the most common and effective method for reducing post-ESD bleeding. ${ }^{17-20}$ Because PPIs are more effective in reducing post-ESD bleeding than $\mathrm{H}_{2}$ receptor antagonists, PPIs are the current treatment of choice for post-ESD bleeding. ${ }^{20}$ Therefore, most endoscopists administer PPIs to patients in the perioperative period. These agents enable faster healing of artificial ulcers induced by ESD. Moreover, because intragastric $\mathrm{pH}>5.4$ promotes blood coagulation and platelet aggregation, the acid-inhibiting effect of PPIs is one of the most important mechanisms that prevent post-ESD bleeding. ${ }^{21}$ However, despite the perioperative use of PPIs, approximately $5 \%$ of patients still experience post-ESD bleeding. ${ }^{22,23}$ As the incidence of post-ESD bleeding is particularly higher in the high-risk group than in the average-risk group, PPI monotherapy is not sufficient to heal ESD-induced artificial ulcers in high-risk patients. ${ }^{24}$ To overcome the limitations of these drugs, new additive methods for preventing post-ESD bleeding have recently been attempted (Table 2). Recently, a potassium-competitive acid blocker (P-CAB) has been developed and vonoprazan has been used in Japan in 2014. It has stronger, faster-acting and longer-lasting gastric acid suppression ef-

Table 2. Results of Various Methods for Preventing Bleeding after Endoscopic Submucosal Dissection (ESD)

\begin{tabular}{|c|c|c|c|c|c|}
\hline Study & Methods & Study design & $\mathrm{N}$ & Enrolled patients characteristics & $\begin{array}{l}\text { Overall post-ESD } \\
\text { bleeding }\end{array}$ \\
\hline $\begin{array}{l}\text { Takizawa et al. }^{27} \\
(2008)\end{array}$ & $\begin{array}{l}\text { Preventive coagulation of } \\
\text { visible vessels }\end{array}$ & Retrospective & 968 & Do not consider specific factors & $\begin{array}{l}\text { Study 52/680 (7.1\%) } \\
\text { Control 11/340 (3.1\%) }\end{array}$ \\
\hline Uedo et al. ${ }^{28}$ (2010) & $\begin{array}{l}\text { Doppler endoscopic } \\
\text { ultrasound }\end{array}$ & Case series & 10 & Do not consider specific factors & $0(0.0 \%)$ \\
\hline Mukai et al. ${ }^{29}$ (2013) & $\begin{array}{l}\text { Preventive coagulation plus } \\
\text { artery-selective clipping }\end{array}$ & Retrospective & 234 & Do not consider specific factors & $\begin{array}{l}\text { Study 1/80 (1.3\%) } \\
\text { Control 7/154 (4.5\%) }\end{array}$ \\
\hline Ikeda et al. ${ }^{33}(2020)$ & Third-look endoscopy & Phase II trial & 96 & Taking with antithrombotics & $\begin{array}{l}\text { Study 6/58 (10.3\%) } \\
\text { Control 12/58 (20.7\%) }\end{array}$ \\
\hline Lee et al..$^{34}(2011)$ & Detachable snare and clips & RCT & 52 & Do not consider specific factors & $\begin{array}{l}\text { Study } 1 / 26(4.0 \%) \\
\text { Control } 0(0.0 \%)\end{array}$ \\
\hline $\begin{array}{l}\text { Kantsevoy et al. }{ }^{35} \\
(2014)\end{array}$ & $\begin{array}{l}\text { Overstitch endoscopic } \\
\text { suturing device }\end{array}$ & Retrospective & 12 & Do not consider specific factors & $0(0.0 \%)$ \\
\hline Tsuji et al. ${ }^{36}(2015)$ & $\begin{array}{l}\text { Polyglycolic acid sheets and } \\
\text { fibrin glue }\end{array}$ & $\begin{array}{l}\text { Nonrandomized trial } \\
\text { with historical control }\end{array}$ & 45 & Do not consider specific factors & $\begin{array}{l}\text { Study 3/45 }(6.7 \%) \\
\text { Control 9/41 (22.0\%) }\end{array}$ \\
\hline $\begin{array}{l}\text { Kawata et al. }{ }^{37} \\
(2018)\end{array}$ & $\begin{array}{l}\text { Polyglycolic acid sheets and } \\
\text { fibrin glue }\end{array}$ & Retrospective & 84 & Taking with antithrombotics & $\begin{array}{l}\text { Study 3/52 (5.8\%) } \\
\text { Control 11/53 (20.8\%) }\end{array}$ \\
\hline Pioche et al. ${ }^{39}$ (2016) & $\begin{array}{l}\text { Self-assembling } \\
\text { matrix-forming gel }\end{array}$ & Retrospective & 22 & Do not consider specific factors & $0(0.0 \%)$ \\
\hline Jung et al. ${ }^{44}(2020)$ & Hemostatic powder & RCT & 143 & $\begin{array}{l}\text { Taking with antithrombotics or } \\
\text { resected specimen size was } \\
\text { expected to be }>40 \mathrm{~mm}\end{array}$ & $\begin{array}{l}\text { Study 4/73 }(5.5 \%) \\
\text { Control 7/50 (7.1\%) }\end{array}$ \\
\hline
\end{tabular}

RCT, randomized controlled trial. 
fects compared with PPI. According to most recently meta-analysis, post ESD bleeding rate were lower in vonoprazan compared with PPI (3.7\% vs. 6.1\%; OR, 0.66; 95\% CI, 0.32 to $1.35 ; P=0.26) .{ }^{25}$ Shiratori et al..$^{26}$ reported the nationwide population-based retrospective cohort study which compared the post-ESD bleeding rates between vonoprazan and PPIs. The vonoprazan group had significantly lower post-ESD bleeding rates than the PPI group (overall: 11.9\% vs. $17.2 \%, P=0.008$; bleeding between days 2 and 30: 7.8\% vs. $11.8 \%, P=0.015){ }^{26}$ However, large number of randomized controlled trial (RCT) are needed to prove the efficacy of $\mathrm{P}-\mathrm{CAB}$ in post-ESD bleeding.

\section{Preventive hemostasis}

According to a previous study, ${ }^{27}$ preventive coagulation of visible vessels in the resection area after ESD may reduce the bleeding rate. The authors reported that meticulous hemostasis of all visible vessels after ESD could decrease the incidence of bleeding from $7.1 \%$ to $3.1 \%$. Uedo et al. ${ }^{28}$ used Doppler endoscopic ultrasound to identify blood vessels in post-ESD ulcers and showed the possibility of reducing bleeding and avoiding unnecessary coagulation. Meanwhile, another study showed that preventive coagulation plus artery-selective clipping tended to reduce the rate of post-ESD bleeding (from $4.5 \%$ to $1.3 \%$ ) better than preventive coagulation alone. ${ }^{29}$ Conversely, excessive hemostasis can lead to delayed perforation or electrocoagulation syndrome. ${ }^{30}$ Therefore, endoscopists should exercise caution not to perform repeated excessive hemostasis. In addition, Doppler endoscopic ultrasound is not widely used in clinical practice because of the difficulty of introducing additional new equipment during ESD. For using Doppler, a 20-MHz pulsed-wave Doppler US unit (VTI Endoscopic Doppler System; Vascular Technology Inc., Nashua, NH, USA) was needed. Although the unit was portable and weighed light, the single-use Doppler probe for EGD was also needed.

\section{Second-look endoscopy}

To date, second-look endoscopies have been reported to have no significant effect in reducing the post-ESD bleeding risk in overall patients. ${ }^{22,23,31,32}$ In addition, no study has fo- cused on the effect of second-look endoscopy on post-ESD bleeding, especially in high-risk patients. Ikeda et al. ${ }^{33}$ reported that third-look endoscopy prevents post-ESD bleeding in patients using antithrombotics. They enrolled 100 patients who were receiving and continuing antithrombotics during ESD. They performed second-look endoscopy on postoperative day 1 and third-look endoscopy postoperative day 5. If oozing of blood or the presence of exposed vessels were observed, prophylactic hemostasis was performed. Delayed post-ESD bleeding was significantly lower in the third-look endoscopy group than in the control group $5.2 \%$ vs. $17.2 \%, P=0.04)$. It is important to identify the subgroup of patients in whom second-look endoscopy can help decrease post-ESD bleeding. Further studies are needed to determine which patient groups will benefit from second-look endoscopy in high-risk patients.

\section{Closing methods}

Closing methods seem to be helpful in preventing post-ESD bleeding. A previous study reported that routine mucosal closure with a detachable snare and clips after ESD promoted earlier healing of iatrogenic ulcers. ${ }^{34}$ Coagulation therapy at the second-look endoscopy was performed more often in the mucosal closure group than in the control group, and the prevalence of open ulcers after 8 weeks was significantly lower in the mucosal closure group than in the control group. However, no significant differences were observed in the incidence of immediate or delayed bleeding between the mucosal closure with clips group and the control group. In addition, another study showed that closure of large mucosal defects after ESD with an overstitch endoscopic suturing device decreased the need for hospitalization. ${ }^{35}$ The study did not compare the post-ESD bleeding rates between the overstitch endoscopic suturing device group and a control group. However, there was no immediate or delayed bleeding in any of the study patients. Therefore, taking the results of these previous studies together, it seems that closing methods help in the healing of iatrogenic ulcers. However, whether closing methods lower the post-ESD bleeding rate remains controversial. Thus, RCTs are warranted. In addition, these methods are technically difficult and require an additional procedure time. Therefore, the convenience of use, technical 
difficulties, and costs of the procedures should be considered when applying these methods in clinical practice.

\section{Shielding method}

PGA sheets are widely applied in surgeries as absorbable materials used to reinforce suturing and prevent bleeding. Tsuji et al. ${ }^{36}$ reported that the application of PGA sheets and fibrin glue showed promising efficacy in preventing post-ESD bleeding. Kawata et al. ${ }^{37}$ also reported that PGA sheets with fibrin glue reduced post-ESD bleeding in high-risk patients who continued to use antithrombotic agents. The incidence of post-ESD bleeding decreased from $20.8 \%$ to $5.8 \%{ }^{37}$ In addition to PGA sheets, the use of bio-sheet graft therapy to prevent adverse events after ESD has been reported in animal models. However, unexpectedly, delayed ulcer healing due to the physical hindrance to the healing process was observed..$^{38}$ Further, these methods are not easy to use because they require technical skills equivalent to those needed for ESD. In another study, Pioche et al. ${ }^{39}$ reported that a gel formed by self-assembling peptides reduced post-ESD bleeding in high-risk patients. This novel extracellular matrix is easy and safe to apply for iatrogenic ulcers after ESD because the material self-assembles at physiological $\mathrm{pH}$ and forms a gel composed of fibers. ${ }^{39}$ However, because the gel is transparent, careful attention must be paid to ensure complete coverage of the resection bed. And, further studies are needed to prove its effectiveness in large numbers.

\section{Hemostatic powders}

Recently, several hemostatic powders have been developed and clinically used in the treatment of gastrointestinal bleeding. Several hemostatic powders are commercially available for clinical use (Table 3, Fig. 1). ${ }^{40,41}$ In an animal study, hemostatic powder application stopped active bleeding caused by snaring in pigs that were administered antithrombotics. ${ }^{42}$ Hemostatic powders absorb water to form a gel matrix that covers the ulcer surface for 3 48 hour and accelerate the physiologic clotting system by enhancing the local concentration of coagulating factors. ${ }^{41,43}$ One of the advantages of hemostatic powder application is that it requires minimal technical expertise because the powder is simply sprayed onto the surface of the post-ESD ulcer site through a catheter, regardless of the anatomical location. In addition, hemostatic powders can be quickly and easily applied to large lesions. Moreover, they do not cause additional secondary tissue injury owing to their noncontact application. Therefore, hemostatic powder application is an effective way to shield the post-ESD ulcer surface and accelerate the physiologic clotting system. In our experience, spraying of hemostatic powder requires a short time and this method is relatively easier to perform than other methods (Fig. 2). Therefore, beginners in ESD can easily apply hemostatic powders to prevent post-ESD bleeding from iatrogenic ulcers. However, there is a learning curve for those who use hemostatic powder for the first time. Especially, hemostatic powder may be affected by gravity, however, most of the powders adheres well to the surface due to moisture on the artificial ulcer after ESD. After endoscopists spray the powder in the target lesion, the remaining powder can accumulate in a gravity dependent manner, however most of it can be applied to the target area. To date, only two studies from our institution have demonstrated the effect of hemostatic powder application on post-ESD bleeding. ${ }^{40,44}$ The first study prospectively enrolled patients at a high risk of post-ESD bleeding. In these patients, bleeding after ESD was treated with hemostatic powder application. ${ }^{40}$ We evaluated the Forrest classification of the post-ESD ulcers on second-look endoscopy and the early or delayed bleeding rates. Although the study was not an RCT, hemostatic powder application showed a promising effect in preventing early post-ESD bleeding in high-risk patients. An interesting finding of this study was that the hemostatic powder was considered to act on bleeding in the early phase. Based on this results, we can expect that hemostatic powder application is more helpful in preventing early post-ESD bleeding than delayed post-ESD bleeding. On the basis of this study, we conducted a multicenter RCT on hemostatic powder application for post-ESD bleeding in high-risk patients. ${ }^{44}$ We enrolled 143 patients (hemostatic powder group, 73; control group, 70). The overall post-ESD bleeding rate was $6.3 \%$, which was much lower than expected. In addition, in the subgroup analysis excluding patients who continued to take antithrombotic agents during ESD, the rate of post-ESD bleeding tended to be lower in the hemostatic powder group than in the 
Table 3. Recently Developed Hemostatic Powders

\begin{tabular}{|c|c|c|}
\hline Name & Composition & Action mechanism \\
\hline Hemospray & Mineral & $\begin{array}{l}\text { Absorption of water } \\
\text { Concentration of platelets and clotting factors }\end{array}$ \\
\hline EndoClot & Polysaccharide & $\begin{array}{l}\text { Absorption of water } \\
\text { Concentration of platelets and clotting factors }\end{array}$ \\
\hline Nexpowder & Biocompatible natural polymer & $\begin{array}{l}\text { Modified of water absorption capacity using coating technology } \\
\text { Reversible cross-linking of amine and aldehyde groups }\end{array}$ \\
\hline CGGEL & $\begin{array}{l}\text { Bioadhesive gels of recombination } \\
\text { human EGF }\end{array}$ & $\begin{array}{l}\text { Absorption of water } \\
\text { Concentration of platelets and clotting factors }\end{array}$ \\
\hline
\end{tabular}

EGF, epidermal growth factor.
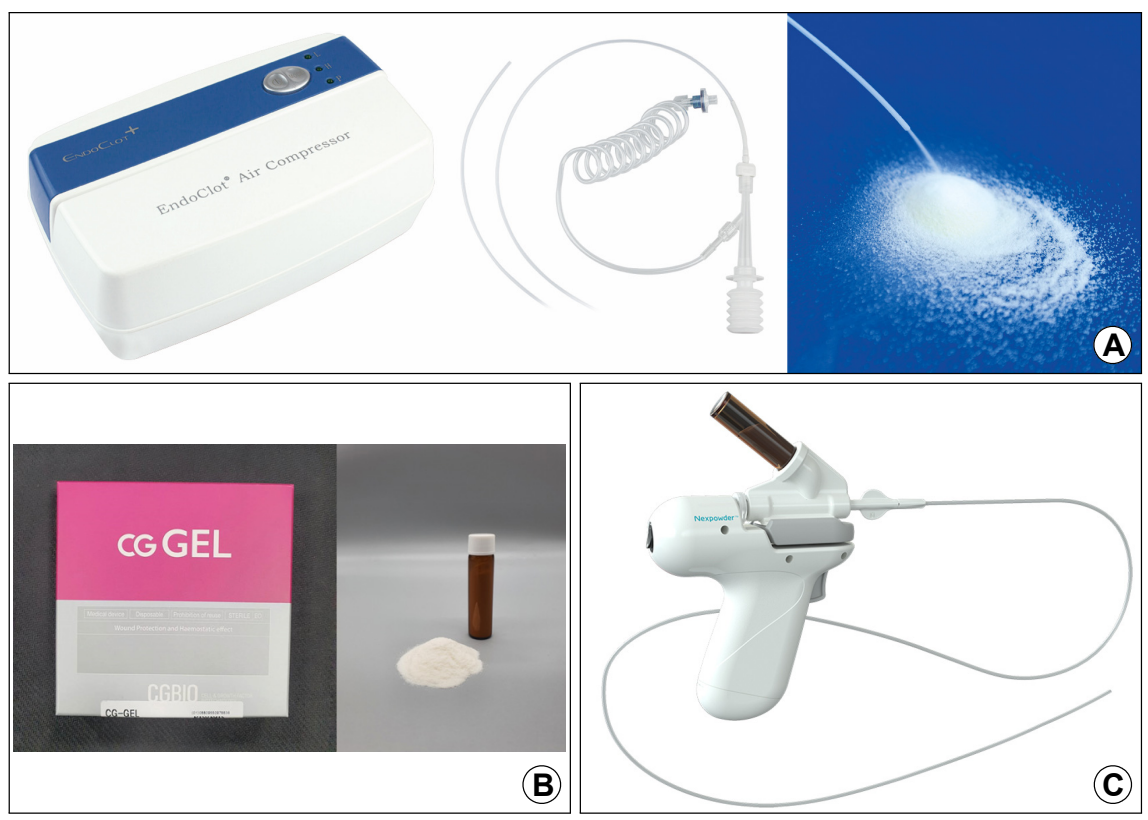

Fig. 1. Hemostatic powders are commercially and clinically available in Korea. (A) Endoclot, (B) CGGEL, (C) Nexpowder.
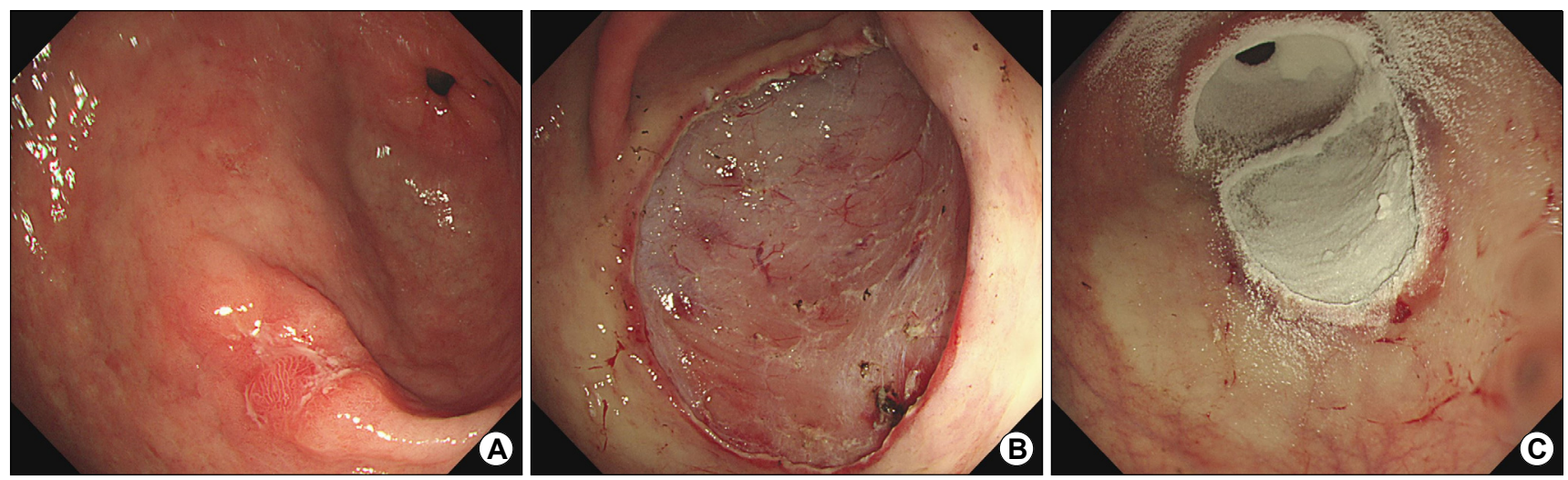

Fig. 2. The endoscopic views show the following. (A) A slightly elevated early gastric cancer with central ulceration at the antrum. (B) A post-resectior ulcer with a maximum diameter of $45 \mathrm{~mm}$ after completion of endoscopic submucosal dissection. (C) The appearance after application of polysaccharide hemostatic powder to surface of the post-resection ulcer. 
control group, although the difference was not statistically significant ( $0 \%$ vs. $6.3 \%, P=0.06$ ). On the basis of these results, it is possible that hemostatic powders can prevent early-phase bleeding in patients undergoing ESD, especially in high-risk patients with a large resected lesion. ${ }^{44}$ Therefore, the role of hemostatic powder application in preventing post-ESD bleeding can be expected in a specific group of patients, considering the advantages this method. Further large-scale RCTs are needed to prove the efficacy of hemostatic powders.

\section{CONCLUSIONS}

Although ESD is an excellent method for the treatment of gastric neoplasms, the appropriate strategy for the prevention and management of post-ESD adverse events is a problem still awaiting a solution. In particular, reducing post-ESD bleeding in high-risk patients is becoming increasingly important. Until now, no existing method can completely prevent post-ESD bleeding. Endoscopists need to always consider the risk of post-ESD bleeding and make maximum efforts to completely avoid this adverse event. Future studies should aim at establishing various methods and materials that are easier to use and have maximal preventive effects against post-ESD bleeding.

\section{CONFLICT OF INTEREST}

No potential conflict of interest relevant to this article was reported.

\section{ORCID}

\author{
Da Hyun Jung \\ (1) https://orcid.org/0000-0001-6668-3113 \\ Jun Chul Park \\ (1) https://orcid.org/0000-0001-8018-0010
}

\section{REFERENCES}

1. Gu L, Khadaroo PA, Chen L, et al. Comparison of long-term outcomes of endoscopic submucosal dissection and surgery for early gastric cancer: a systematic review and meta-analysis. J Gastrointest Surg 2019;23:1493-1501.

2. Li H, Feng LQ, Bian YY, et al. Comparison of endoscopic submucosal dissection with surgical gastrectomy for early gastric cancer: an updated meta-analysis. World J Gastrointest Oncol
2019;11:161-171.

3. Kim YJ, Park DK. Management of complications following endoscopic submucosal dissection for gastric cancer. World J Gastrointest Endosc 2011;3:67-70.

4. Goto O, Fujishiro M, Oda I, et al. A multicenter survey of the management after gastric endoscopic submucosal dissection related to postoperative bleeding. Dig Dis Sci 2012;57:435-439.

5. Koh R, Hirasawa K, Yahara S, et al. Antithrombotic drugs are risk factors for delayed postoperative bleeding after endoscopic submucosal dissection for gastric neoplasms. Gastrointest Endosc 2013;78:476-483.

6. Yano T, Tanabe S, Ishido K, et al. Different clinical characteristics associated with acute bleeding and delayed bleeding after endoscopic submucosal dissection in patients with early gastric cancer. Surg Endosc 2017;31:4542-4550.

7. Park YM, Cho E, Kang HY, Kim JM. The effectiveness and safety of endoscopic submucosal dissection compared with endoscopic mucosal resection for early gastric cancer: a systematic review and metaanalysis. Surg Endosc 2011;25:2666-2677.

8. Dong J, Wei K, Deng J, et al. Effects of antithrombotic therapy on bleeding after endoscopic submucosal dissection. Gastrointest Endosc 2017;86:807-816.

9. Shindo Y, Matsumoto S, Miyatani H, Yoshida Y, Mashima H. Risk factors for postoperative bleeding after gastric endoscopic submucosal dissection in patients under antithrombotics. World J Gastrointest Endosc 2016;8:349-356.

10. Takahashi F, Yoshitake N, Akima T, et al. A second-look endoscopy may not reduce the bleeding after endoscopic submucosal dissection for gastric epithelial neoplasm. BMC Gastroenterology 2014;14:9004.

11. Matsumura T, Arai M, Maruoka D, et al. Risk factors for early and delayed post-operative bleeding after endoscopic submucosal dissection of gastric neoplasms, including patients with continued use of antithrombotic agents. BMC Gastroenterol 2014; 14:172.

12. Ono S, Fujishiro M, Yoshida N, et al. Thienopyridine derivatives as risk factors for bleeding following high risk endoscopic treatments: safe treatment on antiplatelets (STRAP) study. Endoscopy 2015; $47: 632-637$.

13. Takeuchi T, Ota K, Harada S, et al. The postoperative bleeding rate and its risk factors in patients on antithrombotic therapy who undergo gastric endoscopic submucosal dissection. BMC Gastroenterol 2013;13:136.

14. Choe YH, Jung DH, Park JC, et al. Prediction model for bleeding after endoscopic submucosal dissection of gastric neoplasms from a high-volume center. J Gastroenterol Hepatol 2021;36: 2217-2223.

15. Gralnek IM, Stanley AJ, Morris AJ, et al. Endoscopic diagnosis and management of nonvariceal upper gastrointestinal hemorrhage (NVUGIH): European Society of Gastrointestinal Endoscopy (ESGE) guideline - update 2021. Endoscopy 2021;53:300-332.

16. ASGE Standards of Practice Committee, Acosta RD, Abraham NS, et al. The management of antithrombotic agents for patients undergoing GI endoscopy. Gastrointest Endosc 2016;83: 
3-16.

17. Uedo N, Takeuchi Y, Yamada T, et al. Effect of a proton pump inhibitor or an $\mathrm{H} 2$-receptor antagonist on prevention of bleeding from ulcer after endoscopic submucosal dissection of early gastric cancer: a prospective randomized controlled trial. Am J Gastroenterol 2007;102:1610-1616.

18. Tomita T, Kim Y, Yamasaki T, et al. Prospective randomized controlled trial to compare the effects of omeprazole and famotidine in preventing delayed bleeding and promoting ulcer healing after endoscopic submucosal dissection. J Gastroenterol Hepatol 2012;27:1441-1446.

19. Fujishiro M, Chiu PW, Wang HP. Role of antisecretory agents for gastric endoscopic submucosal dissection. Dig Endosc 2013; 25(Suppl 1):86-93.

20. Yang Z, Wu Q, Liu Z, Wu K, Fan D. Proton pump inhibitors versus histamine-2-receptor antagonists for the management of iatrogenic gastric ulcer after endoscopic mucosal resection or endoscopic submucosal dissection: a meta-analysis of randomized trials. Digestion 2011;84:315-320.

21. Green FW Jr, Kaplan MM, Curtis LE, Levine PH. Effect of acid and pepsin on blood coagulation and platelet aggregation. A possible contributor prolonged gastroduodenal mucosal hemorrhage. Gastroenterology 1978;74:38-43.

22. Goto O, Fujishiro M, Kodashima S, et al. A second-look endoscopy after endoscopic submucosal dissection for gastric epithelial neoplasm may be unnecessary: a retrospective analysis of postendoscopic submucosal dissection bleeding. Gastrointest Endosc 2010;71:241-248.

23. Mochizuki S, Uedo N, Oda I, et al. Scheduled second-look endoscopy is not recommended after endoscopic submucosal dissection for gastric neoplasms (the SAFE trial): a multicentre prospective randomised controlled non-inferiority trial. Gut 2015;64:397-405.

24. Wang J, Guo X, Ye C, et al. Efficacy and safety of proton pump inhibitors (PPIs) plus rebamipide for endoscopic submucosal dissection-induced ulcers: a meta-analysis. Intern Med 2014; 53:1243-1248.

25. Martin, Zhou Y, Meng CX, Takagi T, Tian YS. Vonoprazan vs proton pump inhibitors in treating post-endoscopic submucosal dissection ulcers and preventing bleeding: a meta-analysis of randomized controlled trials and observational studies. Medicine (Baltimore) 2020;99:e19357.

26. Shiratori $Y$, Niikura R, Ishii N, et al. Vonoprazan versus proton pump inhibitors for postendoscopic submucosal dissection bleeding in the stomach: a multicenter population-based comparative study. Gastrointest Endosc 2021. doi: 10.1016/j.gie. 2021.06.032. [Epub ahead of print]

27. Takizawa K, Oda I, Gotoda T, et al. Routine coagulation of visible vessels may prevent delayed bleeding after endoscopic submucosal dissection--an analysis of risk factors. Endoscopy 2008;40:179-183.

28. Uedo N, Takeuchi Y, Ishihara R, et al. Endoscopic Doppler US for the prevention of ulcer bleeding after endoscopic submucosal dissection for early gastric cancer: a preliminary study (with video). Gastrointest Endosc 2010;72:444-448.

29. Mukai S, Cho S, Nakamura S, et al. Postprocedural combined treatment using the coagulation plus artery-selective clipping (2C) method for the prevention of delayed bleeding after ESD. Surg Endosc 2013;27:1292-1301.

30. Hirasawa K, Sato C, Makazu M, et al. Coagulation syndrome: delayed perforation after colorectal endoscopic treatments. World J Gastrointest Endosc 2015;7:1055-1061.

31. Libânio D, Costa MN, Pimentel-Nunes P, Dinis-Ribeiro M. Risk factors for bleeding after gastric endoscopic submucosal dissection: a systematic review and meta-analysis. Gastrointest Endosc 2016;84:572-586.

32. Kim JS, Chung MW, Chung CY, et al. The need for second-look endoscopy to prevent delayed bleeding after endoscopic submucosal dissection for gastric neoplasms: a prospective randomized trial. Gut Liver 2014;8:480-486.

33. Ikeda R, Hirasawa K, Sato C, et al. Third-look endoscopy prevents delayed bleeding after endoscopic submucosal dissection under antithrombotic therapy. World J Gastroenterol 2020;26: 6475-6487.

34. Lee BI, Kim BW, Kim HK, et al. Routine mucosal closure with a detachable snare and clips after endoscopic submucosal dissection for gastric epithelial neoplasms: a randomized controlled trial. Gut Liver 2011;5:454-459.

35. Kantsevoy SV, Bitner M, Mitrakov AA, Thuluvath PJ. Endoscopic suturing closure of large mucosal defects after endoscopic submucosal dissection is technically feasible, fast, and eliminates the need for hospitalization (with videos). Gastrointest Endosc 2014;79:503-507.

36. Tsuji Y, Fujishiro M, Kodashima S, et al. Polyglycolic acid sheets and fibrin glue decrease the risk of bleeding after endoscopic submucosal dissection of gastric neoplasms (with video). Gastrointest Endosc 2015;81:906-912.

37. Kawata N, Ono H, Takizawa K, et al. Efficacy of polyglycolic acid sheets and fibrin glue for prevention of bleeding after gastric endoscopic submucosal dissection in patients under continued antithrombotic agents. Gastric Cancer 2018;21:696-702.

38. Kwon CI, Kim G, Ko KH, et al. Bio-sheet graft therapy for artificial gastric ulcer after endoscopic submucosal dissection: an animal feasibility study. Gastrointest Endosc 2015;81:989-996.

39. Pioche M, Camus M, Rivory J, et al. A self-assembling matrix-forming gel can be easily and safely applied to prevent delayed bleeding after endoscopic resections. Endosc Int Open 2016;4:E415-E419.

40. Hahn KY, Park JC, Lee YK, Shin SK, Lee SK, Lee YC. Efficacy of hemostatic powder in preventing bleeding after gastric endoscopic submucosal dissection in high-risk patients. J Gastroenterol Hepatol 2018;33:656-663.

41. Prei JC, Barmeyer C, Bürgel N, et al. EndoClot polysaccharide hemostatic system in nonvariceal gastrointestinal bleeding: results of a prospective multicenter observational pilot study. J Clin Gastroenterol 2016;50:e95-e100.

42. Kaehler G, Dutenhoefner C, Magdeburg R. Endoscopic application of polysaccharide powder for hemostasis in anticoagulated 
pigs (with video). Gastrointest Endosc 2015;82:161-163.

43. Beg S, Al-Bakir I, Bhuva M, Patel J, Fullard M, Leahy A. Early clinical experience of the safety and efficacy of EndoClot in the management of non-variceal upper gastrointestinal bleeding. Endosc Int Open 2015;3:E605-E609.

44. Jung DH, Moon HS, Park CH, Park JC. Polysaccharide hemostatic powder to prevent bleeding after endoscopic submucosal dissection in high risk patients: a randomized controlled trial. Endoscopy 2020. doi: 10.1055/a-1312-9420. [Epub ahead of print]

45. Takahashi F, Yoshitake N, Akima T, et al. A second-look endoscopy may not reduce the bleeding after endoscopic submucosal dissection for gastric epithelial neoplasm. BMC Gastroenterol 2014;14:152.

46. Nakamura M, Nishikawa J, Hamabe K, et al. Risk factors for delayed bleeding from endoscopic submucosal dissection of gastric neoplasms. Scand J Gastroenterol 2012;47:1108-1114.

47. Toyokawa $\mathrm{T}$, Inaba $\mathrm{T}$, Omote $\mathrm{S}$, et al. Risk factors for perforation and delayed bleeding associated with endoscopic submucosal dissection for early gastric neoplasms: analysis of 1123 lesions. J Gastroenterol Hepatol 2012;27:907-912.

48. Sanomura Y, Oka S, Tanaka S, et al. Taking warfarin with heparin replacement and direct oral anticoagulant is a risk factor for bleeding after endoscopic submucosal dissection for early gastric cancer. Digestion 2018;97:240-249.

49. Ebi M, Shimura T, Nishiwaki H, et al. Management of systolic blood pressure after endoscopic submucosal dissection is crucial for prevention of post-ESD gastric bleeding. Eur J Gastroenterol Hepatol 2014;26:504-509.

50. Miyahara K, Iwakiri R, Shimoda R, et al. Perforation and postoperative bleeding of endoscopic submucosal dissection in gastric tumors: analysis of 1190 lesions in low- and high-volume centers in Saga, Japan. Digestion 2012;86:273-280.

51. Hatta W, Tsuji Y, Yoshio T, et al. Prediction model of bleeding after endoscopic submucosal dissection for early gastric cancer: BEST-J score. Gut 2021;70:476-484. 